\title{
Modelling the Design of a Centrifugal Pump Shaft that can Withstand Fatigue Failure Rate, Stress and Strain during Backpressure
}

\author{
P. B. Sob \\ Departmentof Mechanical Engineering, Faculty of Engineering and Technology, \\ Vaal University of Technology, Vanderbijlpark 1900, Private Bag X021, South Africa
}

ORCID: 0000-0002-1796-7694

\begin{abstract}
There are several centrifugal pump shaft failures due to backpressure and that has led to random breakdown in most pump industries. Researchers and engineering have made several attempts in designing a better centrifugal pump shaft that can withstand backpressure. In the current paper a centrifugal pump shaft is designed to withstand backpressure by modeling the stress and strain on the shaft during backpressure. The tool of Auto desk fusion 360 was used to analyze the relationship between back pressure intensity, stress and strain when the shaft is constrained on the drive end bearing and non-drive end bearing using frictionless constrain at extreme back pressure.

The following facts were revealed after empirical modelling and simulation of the major parameters or variable of stressstrain relationship. The pump shaft shows low possibility of failure rate at the keyway slot. As the shaft was subjected to more stress and strain the due to increase in back pressure the initial failure zone in the material start propagating throughout the shaft spindle. As the stress intensity increases the material experience high stress and strain intensity and the possibility that the material can experience fatigue and failure start increasing. The obtained results revealed that the material stress is linearly related to strain by Hooke's law. The results revealed a straight line until to the yield strength of $207 \mathrm{MPa}$ is attained. The modelled shaft deigned in this study can withstand backpressure and the possibility of material failure due to material fatigue is very limited.
\end{abstract}

Keywords: stress, strain, failure, fatigue, centrifugal pump, and backpressure

\section{INTRODUCTION}

Shaft Fatigue is a form of failure that occurs in centrifugal pump shaft due to dynamic and fluctuating stresses. It is possible for a shaft failure to occur at a stress level considerably lower than the tensile or yield strength for a static load (AZEEZ, 2013). Shaft Fatigue is also a failure that normally occurs after a lengthy period of repeated stress or strain cycling (Gedney, February 1, 2019). Shaft Fatigue is important in as much as it is the single largest cause of failure in centrifugal pumps during operation and most studies shown that most of centrifugal pump fails due to shaft fatigue (Ali Naeem Odaa, 2017). Centrifugal pump shaft fail under various modes as determined by buckling, deflection, natural frequency, strain, or stress (FAA, 2000). Strain or stress failure criteria are different depending on whether they are considered as brittle or ductile materials. The difference between brittle and ductile material behaviors is determined by their response to a uniaxial stress-strain test (A. Pineau a, 2015).

For stable design, it is important to look at the maximum shear stress theory (M.S.S.T) of shaft during backpressure that often led to material fatigue and failure. The maximum shear stress theory in a shaft is also termed as Guest and Tresca's theory and this theory is used mostly in ductile materials (Abdul, 2019). According to the theory of maximum shear stress, the failure of a centrifugal pump shaft due to back pressure will occur when the maximum value of shear stress developed in the body exceeds the limiting value of shear stress and strain during operation. This failure rate or fatigue rate can be predicted from the fundamental stress and strain relationship which revealed material plasticity and elasticity during stress and strain process given by Fig.1.

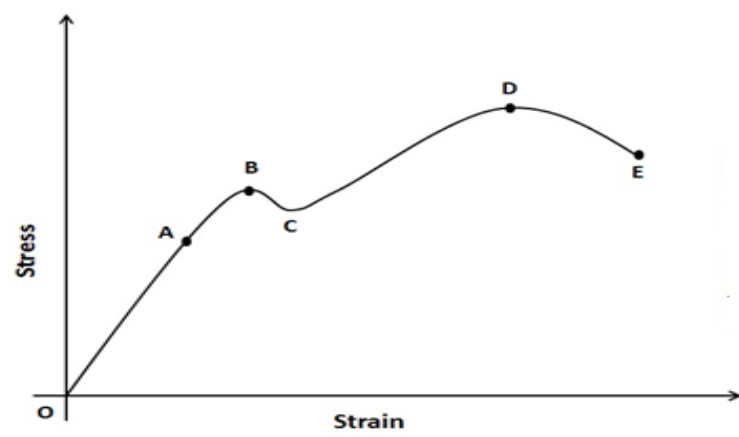

Figure 1. Stress and strain relationship for a ductile material (Roylance, 2001)

Where A is proportionality limit; up to this point hooks law remain valid during stress and strain process, $\mathrm{B}$ is the elastic limit, up to this point the deformation will be elastic, $\mathrm{C}$ is lower yield stress, $D$ is the ultimate stress, it is the maximum value of stress in stress, strain diagram and $\mathrm{E}$ is the fracture point, up to this point the shaft material will have only elastic \& plastic deformation ,but at this point fracture or rupture take place. If maximum value of shear stress and strain developed in the centrifugal pump shaft exceeds the value of shear stress corresponding to the point $\mathrm{D}$, failure will take place. Therefore, to avoid the condition of failure of the shaft, maximum value of shear stress and strain developed in the shaft must be below than the value of shear stress corresponding to the point $D$. 
Hook's law state that within elastic limit, stress applied over an elastic shaft material will be directionally proportional to the strain produced due to external applied stress due to loading.

Material stress is a measure of the force per unit area acting on a plane passing through the point of interest in a centrifugal pump shaft (Richard Leach, 2018) . Strains are multiplied by shaft material properties to define a new physical quantity and the stress, which is directly proportional to the strains display the distortional energy failure theory which is usually called the Von Misses stress, or effective stress. The von misses effective stress is compared to the material yield stress for ductile materials and for brittle materials higher safety factor must be used. Failure is mostly predicted to occur based on the distortional energy stored in the centrifugal pump shaft material and when the von Misses value reaches the yield stress. The maximum shear stress is predicted to cause failure when it reaches half the yield stress of the shaft (Akin, 2009) and distortion of energy and failure may take place.

Distortion energy theory for centrifugal pump shaft fatigue failure are always analysis using maximum stress values due to the system combined loading of bending and torsion during operation. Distortion energy theory are used to predicts failure in a shaft especially in materials that are ductile. Most design computation and modelling involved theory that are more complicated as compared to other theories of failure. According to the distortion energy theory, there are two types of problems in fatigue design- components which are subjected to completely reversed stresses leading to material strain, and components subjected to fluctuating stresses which leads to material straining, where the mean stress being zero in case of completely reversed stresses. In a centrifugal pump shaft experiencing backpressure such stress due to fluctuation causes a straining problem in the shaft during operation and this often leads to material fatigue and failure in the shaft during operation. In most cases during centrifugal pump operation, backpressure causes fluctuating stresses leading to subsequent straining and shaft failure. There are mean stresses in the shaft during operation that causes mean strain, the centrifugal pump shaft mean stresses and straining can be purely tensile, purely compressive or mixed depending upon the magnitude of mean stress and strain subjected to the shaft during backpressure. In the past such problem can be controlled using modified Goodman diagram (Bhandari., 2010). The main setback faced is lack of proper study on the theory of centrifugal pump shaft failure during straining process when the shaft is subjected to backpressure.

The theory of failure during back pressure help us to determine the safe dimensions of a centrifugal pump shaft when it is subjected to combined stresses and strain due to various loading condition during back pressure. From such combined stresses and straining the theories of failure during back pressure can applicable in proper designing of a centrifugal shaft that are impacted by material stresses and straining that leads to material fatigue and failure when subjected to combined loading conditions. The theory of failure during back pressure will play a key role in establishing the relationship between stresses induced under combined loading conditions, straining due to the combined loading condition which impacts material stability during backpressure. In most causes the material properties (stress and strain) exceed the design ultimate tensile strength (Sut) and yield strength (Syt) due to backpressure leading to fatigue and failure that are unpredicted. Researchers have not done significant study on centrifugal pump shaft and material failure due to high stress and strain during backpressure that often leads to fatigue. Most studies on centrifugal pump shaft defects prediction focus on cavitation and Net positive suction or Thomas cavitation with designing a proper shaft that can withstand stress and strain during backpressure. These has often led to several fatigue problem in a centrifugal pump shaft due to backpressure. In this study the stress and strain process in a centrifugal pump shaft during backpressure are modelled theoretically and computed with an Auto desk fusion 360. The modelling and computation are subjected to back pressure intensity, stress and strain when the shaft is constrained to a drive end bearing and non-drive end bearing using frictionless constrain at extreme back pressure.

\section{METHODOLOGY}

To model the condition for shaft design safety during backpressure that causes high stress and straining that often led to material fatigue, the principal stress maximum principal stress $\left(\sigma_{1}\right) \leq \operatorname{permissiblestress}\left(\sigma_{\text {per }}\right)$ given as $\sigma_{\text {per }}=\frac{\text { failure stress }}{\text { factor of safety }}=\frac{s_{\mathrm{yt}}}{\mathrm{N}}$ or $\frac{\mathrm{s}_{\mathrm{ut}}}{\mathrm{N}}$ are often used in the modelling and computational process. For safety condition the maximum principal stress should hold on the following condition given as $\sigma_{1} \leq \frac{s_{\mathrm{yt}}}{\mathrm{N}}$ or $\frac{\mathrm{s}_{\mathrm{ut}}}{\mathrm{N}}$. This Theory are more suitable for the safe design of centrifugal pump shaft made from brittle materials under varying loading conditions such as triaxial, biaxial and hydrostatic stress because brittle materials are weak in tensioning, unsuitable in any safe design of machine components made of ductile materials because ductile materials are weak in shear due to high stress and strain process. This theory can be suitable for the safe design of machine components made of ductile materials under following state of stress conditions such as uniaxial state of stress given as ( $\tau_{\max }=\frac{\sigma_{1}}{2}$ ), biaxial state of stress when principal stresses is given as $\left(\tau_{\max }=\frac{\sigma_{1}}{2}\right)$ and hydrostatic stress condition (shear stress and strain in all the planes is zero). The condition for failure during back pressure defined the maximum shear stress induced at a critical point under triaxial combined stress must be greater than the yield strength in shear under tensile given as

$$
\tau_{\max }>s_{\mathrm{ys}} \text { or } \frac{s_{\mathrm{yt}}}{\mathrm{N}}
$$

The condition for safe design during back pressure can be defined by looking at the condition of failure during back pressure given as the Maximum Principal strain $\left(\varepsilon_{1}\right)>$ Yielding strain under tensile test $\left(\varepsilon_{\mathrm{YP}}\right) \varepsilon_{1}>$ $\left(\varepsilon_{\mathbf{Y P}}\right)$ or $\frac{s_{y t}}{\mathrm{E}} \boldsymbol{w}$ here $\mathrm{E}=$ Young's Modulus of Elasticity. The condition for safe design during back pressure

Maximum Principal strain $\leq$ Permissible strain is given as Permissible strain $=$

$$
\frac{\text { Yielding strain under tensile test }}{\text { Factor of safety }}=\frac{\left(\varepsilon_{\text {YP }}\right)}{\mathrm{N}}=\frac{s_{y t}}{\mathrm{EN}}
$$


International Journal of Engineering Research and Technology. ISSN 0974-3154, Volume 13, Number 10 (2020), pp. 2927-2934

(C) International Research Publication House. https://dx.doi.org/10.37624/IJERT/13.10.2020.2927-2934

$\varepsilon_{1} \leq \frac{s_{y t}}{\mathrm{EN}}$

The Tri-axial state and Bi-axial state during shaft operation are given as

$\frac{1}{\mathrm{E}}\left[\sigma_{1}-\mu\left(\sigma_{2}+\sigma_{3}\right)\right] \leq \frac{s_{y t}}{\mathrm{EN}}$

$\left[\sigma_{1}-\mu\left(\sigma_{2}+\sigma_{3}\right)\right] \leq \frac{s_{y t}}{\mathrm{~N}}$

Bi-axial state, $\sigma_{3}=0$

$\left[\sigma_{1}-\mu\left(\sigma_{2}\right)\right] \leq \frac{s_{y t}}{\mathrm{~N}}$

From equation (4) to (6) the total strain and strain energy can be computed in the shaft during backpressure. The total strain Energy theory or Beltrami-Haigh predicts the failure of a centrifugal pump shaft subjected to any combination of loads when the strain energy per unit volume of any portion of the stressed member reaches the failure value of strain energy per unit volume as determined from an axial or compression test of the same material. The total strain energy per unit volume is given by the sum of the energy component due to three principal stresses and strains. The condition of failure during back pressure is given as Total Strain Energy per unit volume > Strain energy per unit volume at yield point.

The strain energy per unit volume can be given as

Strain energy per unit volume up to Elastic limit (E. L) $=$

$$
\frac{1}{2} \sigma_{\mathrm{E} . \mathrm{L}} \cdot \varepsilon_{\mathrm{E} . \mathrm{L}}
$$

The tri-axial strain energy during operation can be defined as

Total Strain Energy per unit volume(T.S. E./vol) =

$$
\frac{1}{2} \sigma_{1} \cdot \varepsilon_{1}+\frac{1}{2} \sigma_{2} \cdot \varepsilon_{2}+\frac{1}{2} \sigma_{3} \cdot \varepsilon_{3}
$$

$\varepsilon_{1}=\frac{1}{\mathrm{E}}\left[\sigma_{1}-\mu\left(\sigma_{2}+\sigma_{3}\right)\right]$

$$
\begin{aligned}
& \varepsilon_{2}=\frac{\mathbf{1}}{\mathrm{E}}\left[\sigma_{2}-\mu\left(\sigma_{1}+\sigma_{3}\right)\right] \\
& \varepsilon_{3}=\frac{1}{\mathrm{E}}\left[\sigma_{3}-\mu\left(\sigma_{1}+\sigma_{2}\right)\right]
\end{aligned}
$$

Where $\mathrm{E}$ is the young's modulus in the system during operation and from equation $(9-11)$ the principal equation of shaft strain rate during backpressure can be defined as

$\varepsilon_{1}=\frac{d}{d t}\left(\frac{1}{\mathrm{E}}\left[\sigma_{1}-\mu\left(\sigma_{2}+\sigma_{3}\right)\right]\right)$
$\varepsilon_{2}=\frac{d}{d t}\left(\frac{1}{\mathrm{E}}\left[\sigma_{2}-\mu\left(\sigma_{1}+\sigma_{3}\right)\right]\right)$
$\varepsilon_{3}=\frac{d}{d t}\left(\frac{1}{\mathrm{E}}\left[\sigma_{3}-\mu\left(\sigma_{1}+\sigma_{2}\right)\right]\right)$

Equation (1-14) are solved simultaneously with an Auto desk fusion 360 when the shaft was subjected to back pressure intensity, stress and strain and the shaft was constrained to a drive end bearing and non-drive end bearing using frictionless constrain at extreme back pressure and the following results are revealed as discussed in the study.

\section{RESULTS AND DISCUSSION}

An Auto desk fusion 360 was used in the current study to analyze the strain the shaft experienced during backpressure. The material strain revelaled a change in length of the pump shaft from original length due to induced backpressure during operation as shown in Fig. 2 to Fig. 10. The material proportionality constant depends on the shape and composition of the pump shaft and the direction of the back pressure during operation. During simulation process, the force due to backpressure was induced on the pump shaft leading to material fatigue and failure due to abnormal stresses and strain as shown in Fig. 2 to Fig. 10. In the current study, the stress and strain that lead to subsequent material deformation due to backpressure was computed and simulated in 3 direction (X, Y and Z). Deformations that are applied perpendicular to the cross section are normal strains, while deformations applied parallel to the cross section are shear strains. To analyze the obtained results revealed in the study, different colors are used and these color depicts different material failure mode as shown in table 1 .

Table 1: Material failure mode classification during simulation process

\begin{tabular}{|c|c|c|c|c|}
\hline \multicolumn{5}{|c|}{ failure $\rightarrow$} \\
\hline A & B & C & D & E \\
\hline Medium & High & High & Extreme & Extreme \\
\hline 5 & 10 & 15 & 20 & Extreme \\
\hline Medium & Medium & High & High & 16 \\
\hline 4 & 8 & 12 & High & Extreme \\
\hline Low & Medium & Medium & 15 \\
\hline 3 & 6 & 9 & High & Extreme \\
\hline Low & Low & Medium & 10 \\
\hline Negligible & 4 & 6 & High & Extreme \\
\hline 1 & Low & Medium & 5 \\
\hline
\end{tabular}


From table 1 it is shown that different failure rate is normally observed due to varying loading condition of stress and strain during backpressure. The color description presented on table 1 as revealed by an Autodesk fusion 360 revealed five different colors. The blue color revealed negligible failure in the shaft during operation. Green revealed the possibility of failure but at a low failure rate during operation. Green is the initiation phase in material failure during backpressure. Yellow revealed a possibility of medium failure due to the initiation of failure revealed by green. The orange represents a possibility of high failure occurrence during backpressure and red revealed extreme failure mode due to backpressure. Figure 2 revealed the shaft being subjected to a backpressure of $10 \mathrm{MPa}$ and the material starts to suffer from stress that increases material strain and material failures are being initiated but at the very low rate and therefore the material is stable with little possibility of fatigue and failure during backpressure. As the stress intensity increases from Fig. 3 to Fig.10 the material experience high stress and strain intensity and the possibility that the material can experience fatigue and failure start increasing. From the observed results the material revealed different growth of initial failure modes from the key zone where the stress intensity in the material is very high and the stress and strain start propagating externally. The modelled shaft deigned in this study can withstand backpressure and the possibility of material failure due to material fatigue is very limited as shown in Fig. 2 to Fig. 10.
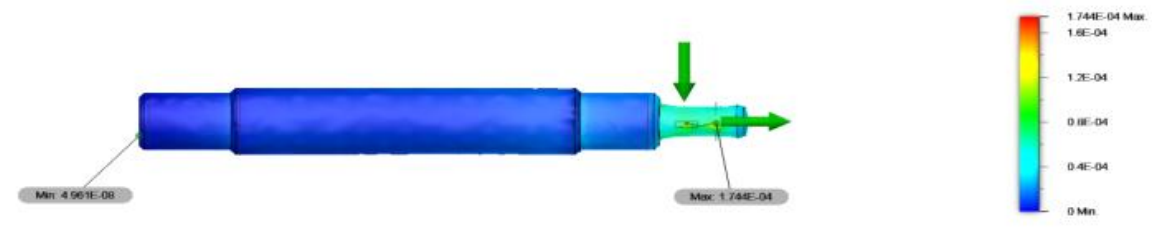

Figure 2 Strain effect on the shaft at a stress of $10 \mathrm{MPa}$ during backpressure
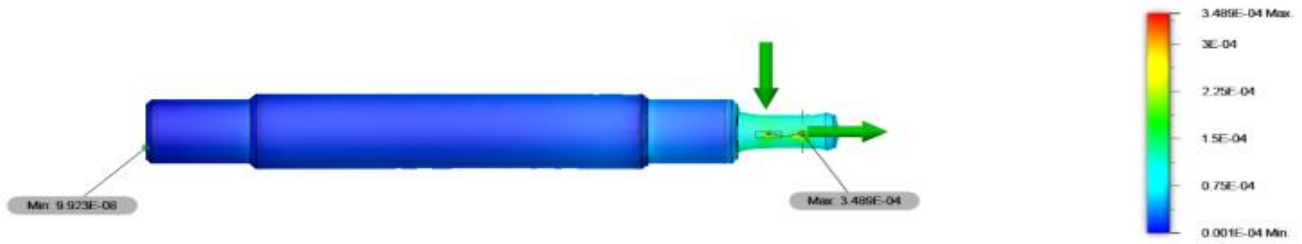

Figure 3 Strain effect on the shaft at a stress of $20 \mathrm{MPa}$ during backpressure
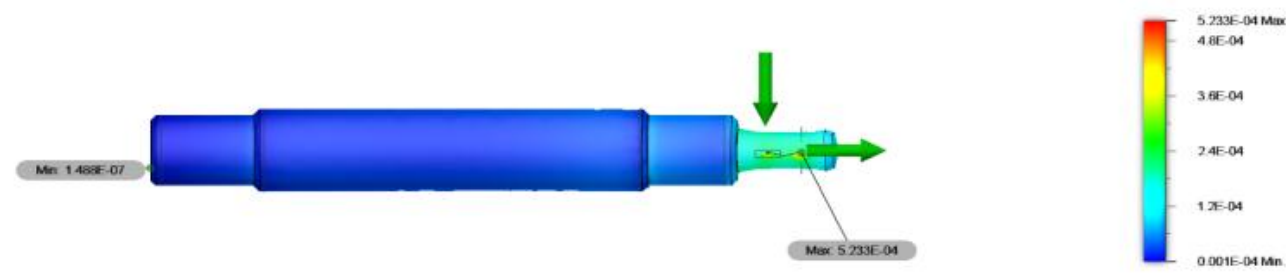

Figure 4 Strain effect on the shaft at a stress of $30 \mathrm{MPa}$ during backpressure 

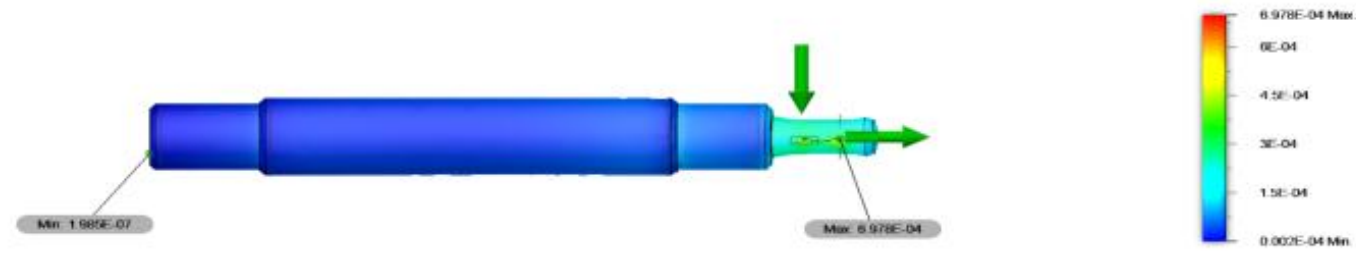

Figure 5 Strain effect on the shaft at a stress of $40 \mathrm{MPa}$ during backpressure
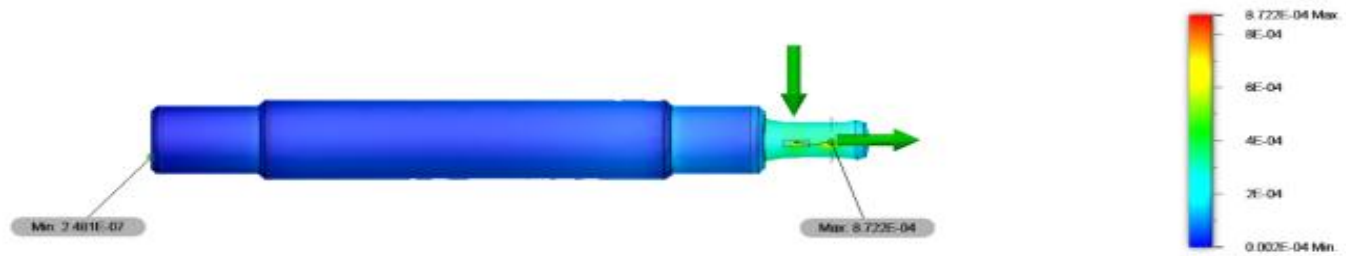

Figure 6 Strain effect on the shaft at a stress of $50 \mathrm{MPa}$ during backpressure
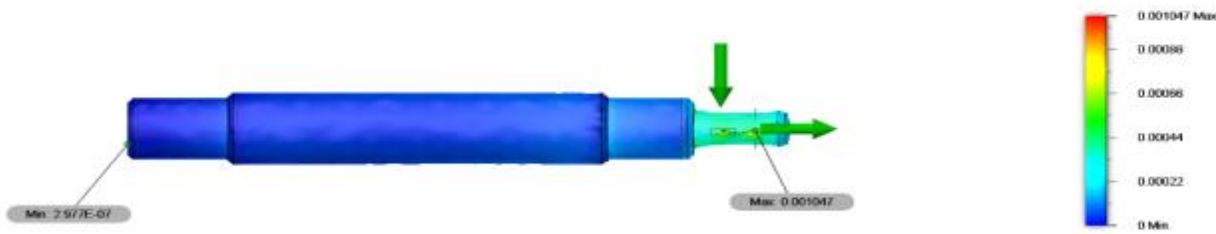

Figure 7 Strain effect on the shaft at a stress of $60 \mathrm{MPa}$ during backpressure

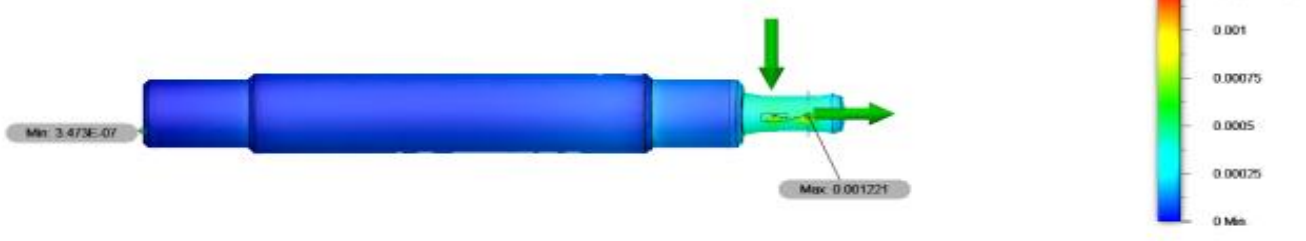

Figure 8 Strain effect on the shaft at a stress of $70 \mathrm{MPa}$ during backpressure 

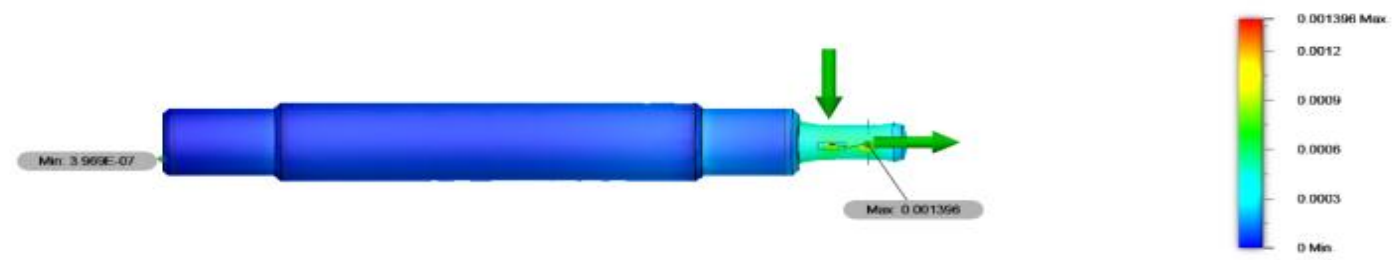

Figure 9 Strain effect on the shaft at a stress of $80 \mathrm{MPa}$ during backpressure
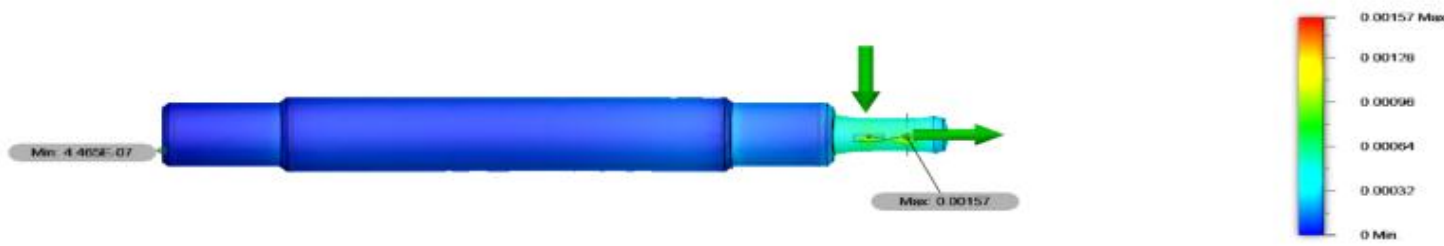

Figure 10 Strain effect on the shaft at a stress of $90 \mathrm{MPa}$ during backpressure
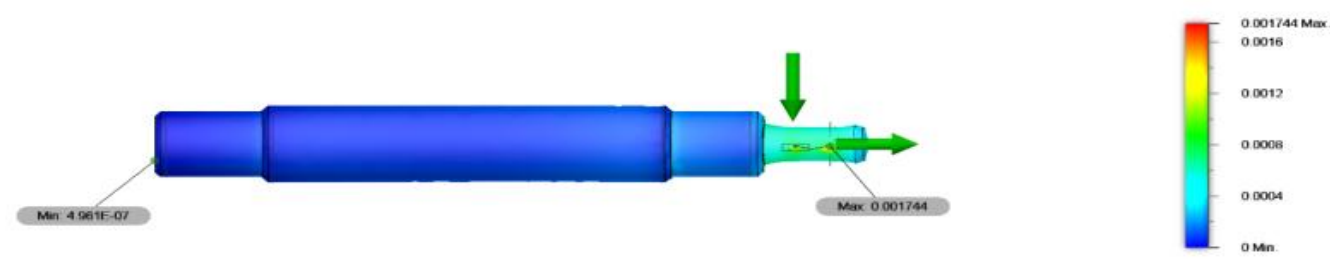

Figure 10 Strain effect on the shaft at a stress of $100 \mathrm{MPa}$ during backpressure

The results shown in Figure 2 to Figure 10 revealed an icrease in backpressure during pump operation have an impact on gradually change of length especially on the shaft spindle. It is observed that the green color are being destributed on the surface area of the spindle showing low strain on the pump shaft and the key way duirng operation. That is the critical zone experiencing high change in length represented by a red dot showing extreme strain ranging from $1.74 \mathrm{e}-05$ to 0.001744 .
The more back pressure is increased the higher the strain on the zone experiencing maximum stress and strain and the possibility of material failure increases. The observed results shows that strain is directly proportional to back pressure,meaning when the back pressure is increased to high rate, the higher the pump shaft will strain and the posibility of material fatigue and subsequent failure increases. 


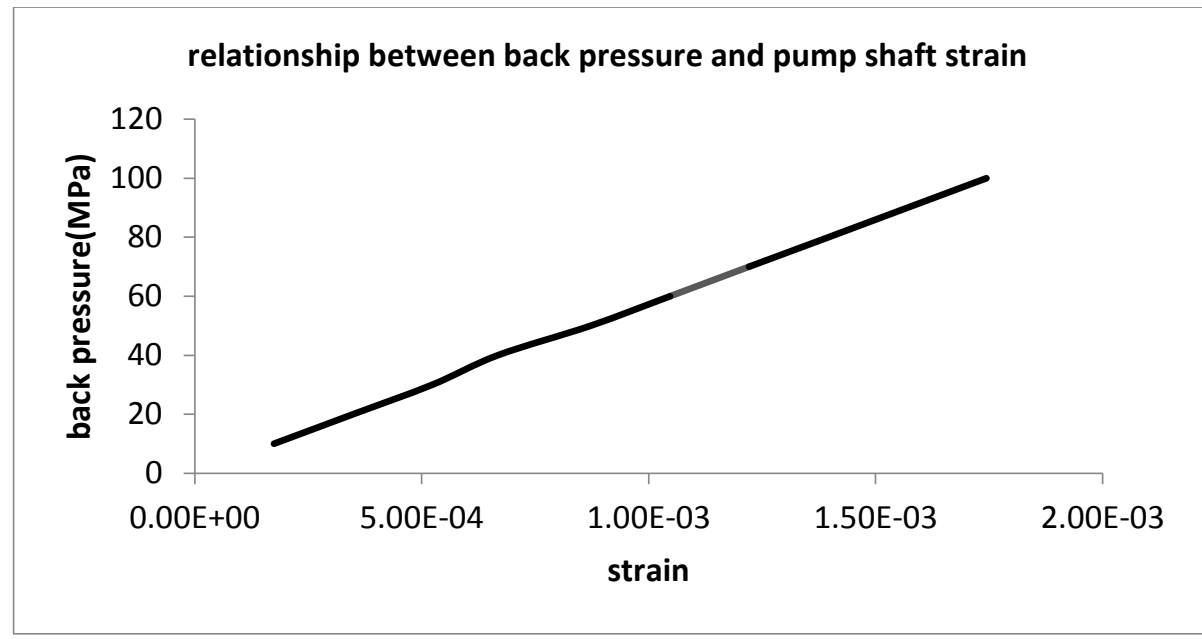

Figure 11 Strain effect on backpressure during operation

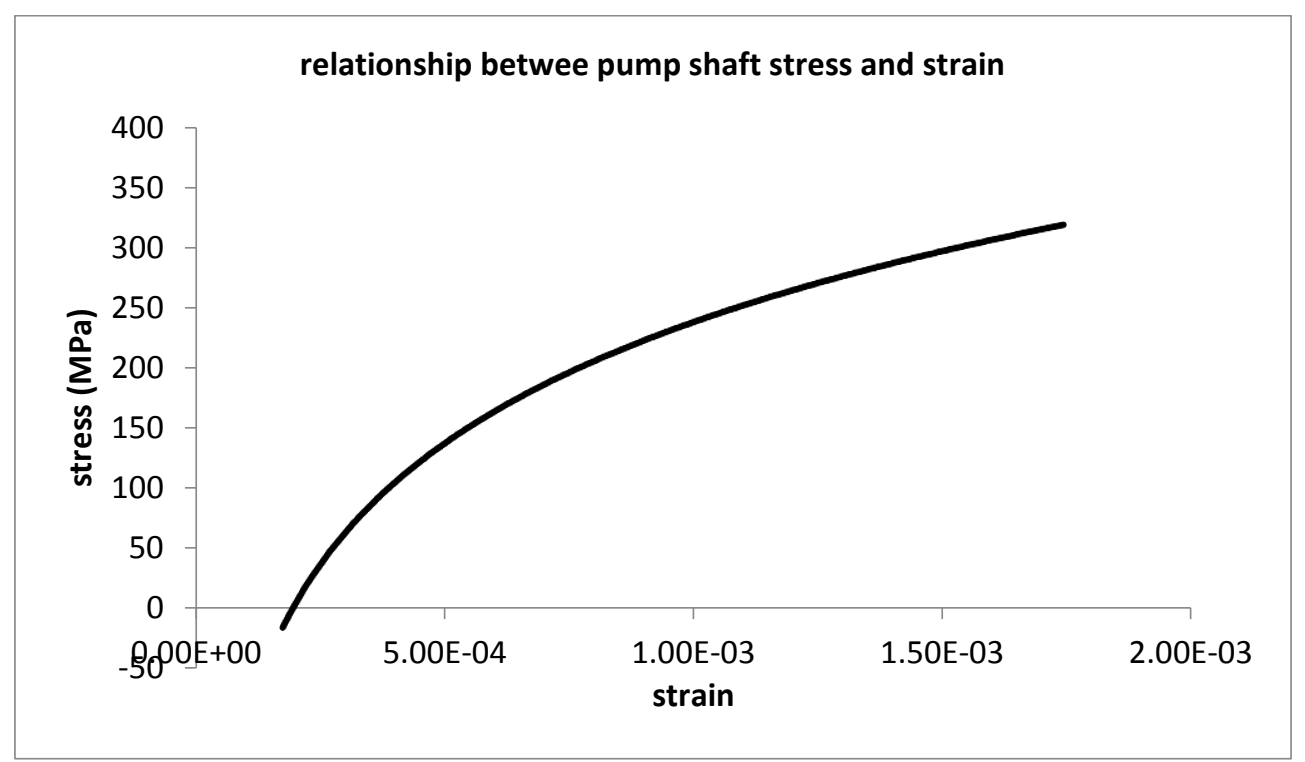

Figure 12 Stress effect on strain during backpressure

The obtained results in Fig.11 and Fig.12 revealed that the material stress is linearly related to strain by Hooke's law. The proportionality of the relationship is acknowledged as the material's elastic modulus due to increase straining on the material during backpressure. If the back pressure is small the ratio of the stress and strain will remain proportional as shown in Fig. 11 which revealed linear relationship between stress and backpressure. At this stage there is no possibility of material experiencing fatigue and failure during operation. The results revealed by Fig. 11 revealed a straight line until to the yield strength of $207 \mathrm{MPa}$ is attained but since we are dealing with highly gradually increased back pressure, pump shaft will experience elastic deformation but the ratio of stress and strain will not be proportional meaning beyond elastic limit, the pump shaft will experience plastic deformation. Figure 12 revealed an increased in stress led to an exponential increase in material straining, not the shaft does not experience plasticity during backpressure. Therefore, the design shaft can withstand backpressure during operation.

\section{CONCLUSION AND RECOMMENDATION}

The aim of this paper was to study the stress and strain in a centrifugal pump shaft during backpressure. To achieve the aim of the study the relevant models for stress and strain were established under defined sets of condition. The derived models where analyse and simulated theoretically with an Auto desk fusion 360 and the following results were revealed. It was shown that the pump shaft shows low possibility of failure rate at the keyway slot. It was also shown that as when the shaft was subjected to more stress and strain the due to increase in back pressure the initial failure zone in the material start propagating throughout the shaft spindle. It was also revealed that as the stress intensity increases the material experience high stress and strain intensity and the possibility that the material can experience fatigue and failure start increasing. It was however revealed that that the material stress is linearly related to strain by Hooke's law. It could be concluded that modelled shaft deigned in this study can withstand backpressure and the 
International Journal of Engineering Research and Technology. ISSN 0974-3154, Volume 13, Number 10 (2020), pp. 2927-2934

(C) International Research Publication House. https://dx.doi.org/10.37624/IJERT/13.10.2020.2927-2934

possibility of material failure due to material fatigue is very limited.

\section{REFERENCES}

A.Barmin1, V. B. (2016). Microstructure and mechaMicrostructure and mechanical properties of silicon carbide ceramics reinforced with multi-walled carbon nanotubesnical properties of silicon carbide ceramics reinforced with multi-walled carbon nanotubes. 7 .

A. Pineau a, A. B. (2015). Brittle and ductile fracture.

Abdul, P. D. (2019). Failure Theories.

Akin, J. (2009). Concepts of Stress Analysis.

Ali Naeem Odaa, Y. Y. (2017). Numerical Simulation and Life Prediction of Stepped Shaft Under Biaxial Fatigue Loading.

Almasi, A. (2015). How to Optimize Centrifugal Pump Operation.

AZEEZ, A. A. (2013). FATIGUE FAILURE AND TESTING METHODS.

B. Engel, S. S.-M. (2017). Failure Analysis and Fatigue Life Estimation of a Shaft of a Rotary Draw Bending Machine.

Bansal, R. K. (n.d.). Strength of material.

Bhandari, V. (0000). Introduction to Machine Design.

Bhandari., V. (2010). DESIGN FOR COMBINED LOADING $\&$ THEORIES OF FAILURE.

Budris, R. (2016). CENTRIFUGAL PUMP FLOW OPERATING REGIONS AND IMPACT ON RELIABILITY.

D.G. Papageorgiou, K. K. (2018). Fracture analysis of a cooling water pump shaft.

Dimitris G. Papageorgiou, K. A. (2018). Fracture analysis of a cooling water pump shaft.

divedi, h. (2017). MAXIMUM PRINCIPAL STRAIN THEORY.

Dr. B. P. Patel, H. R. (2014). Critical Review on design of shaft with multiple discontinuities and combined,Dutt. B. Thakar.

e, E. n. (2011). transient analysis.

E.R Tomblin, K. B. (2013). CROSS-CONNECTIONS AND BACKFLOW PREVENTION MANUAL.

F. Berndt, A. v. (1999). Pump shaft failures $Đ$ a compendium of case studies.

FAA. (2000). Analysis Techniques.

G.Das, A. S. (1998). Failure analysis of counter shafts of a centrifugal pump.

Gedney, R. (February 1, 2019). Stress-Life Fatigue Testing Basics.
Goran Vukelic 1, *. a. (2016). Predicted Fracture Behavior of Shaft Steels with.

Gulich, J. (2008). centrifugal pumps.

Karney, X. X. (2017). An Overview of Transient Fault Detection.

Kristoffer K. McKee, G. F. (n.d.). A review of major centrifugal pump failure modes with.

KSB. (2018). back pressure speed.

N. Pasca, L. S. (2010). FAILURE ANALYSIS OF A STORAGE PUMP SHAFT.

N.RAJENDAR, .. N. (2017). DESIGN AND ANALYSIS OF COMPOSITE DRIVE SHAFT.

Preven, J. F. (2010). Failure Analysis of Water Pump Shaft. pvm rao, m. s. (2005). Carbon nanotubes as machine elements. 4.

Richard Leach, . T. (2018). basic of precision engineering.

Rosen, H. (2010). Variability of pump system performance.

Roylance, D. (2001). Introduction to Fracture Mechanics. 2-3.

Roylance, D. (2001). STRESS-STRAIN CURVES.

staff, e. e. (2012). Failure Analysis Of Machine Shafts.

world, w. (2016). RELIABILITY, CENTRIFUGAL PUMP FLOW OPERATING REGIONS AND IMPACT ON.

Wuyi Wan, B. Z. (2018). Investigation on Water Hammer Control of Centrifugal Pumps in Water Supply Pipeline Systems. 